\title{
Nucleoli in large (giant) bi- and multinucleate cells after apoptosis-inducing photodynamic treatment
}

\author{
K. Smetana, Z. Hrkal \\ Institute of Hematology and Blood Transfusion, Prague, Czech Republic
}

\section{(C)2003, European Journal of Histochemistry}

The present experimental study was undertaken to provide information on nucleolar changes accompanying the apoptotic process in large or giant binucleate and multinucleate cells (LBMNCs). Such cells were present in a small but constant percentage in cultures of HL-60 cells. The apoptotic process was induced by photodynamic treatment (PDT) by means of 5-aminolaevulinic acid (ALA) as the precursor of the photosensitizer protoporphyrin IX and irradiation with broad spectrum blue light $(\mathrm{BL})$. Nucleolar changes in LBMNCs were characterized by marked reduction or disappearance of silver stained particles representing AgNORs in nucleoli including the large ones. In addition, PDT also significantly reduced the number of nucleoli regardless of their size. These changes apparently reflected the decrease or cessation of nucleolar biosynthetic activities and resembled those which were previously observed in naturally maturing bone marrow megakaryocytes (Janoutová et al., 2001).

Key words: apoptosis, photodynamic treatment, nucleolus

Correspondence: Dr. Karel Smetana, Institute of Hematology and Blood Transfusion, U nemocnice 1, Prague 2, Czech Republic, 12820.

Fax: international +420.2.21977249.

E-mail: karel.smetana@uhkt.cz

Paper accepted on October 5, 2002

European Journal of Histochemistry 2003; vol. 47 issue 1 [Jan-Mar]:39-44
$\mathrm{R}$ ecent studies demonstrated that the photodynamic treatment (PDT) using 5-aminolaevulinic acid ( $A L A$ ) as the precursor of the photosensitizer protoporphyrin IX and blue light (BL) irradiation induced the apoptotic process in mononuclear leukemic granulocytic precursor cells HL-60 (Grebenová et al., 1998). The induced apoptotic process, however, was not accompanied by terminal cell maturation in contrast to naturally occurring programmed cell death (Smetana et al., 2000, Smetana, 2002). PDT-induced apoptotic process took place by the reduction of AgNORs without nucleolar transformation into micronucleoli. On the other hand, no satisfactory information is available on nucleolar changes produced by the apoptotic process in large (giant) binucleate and multinucleate cells (LBMNCs) of hematopoietic origin. In maturing polyploid megakaryocytes representing LBMNCs with irregularly segmented polymorphic nuclei (Undritz, 1972), the number of nucleoli and AgNORs decreased to half values in naked megakaryocyte nuclei which are considered as the last developmental stage of this cell lineage (Janoutová et al., 2001). The number of nucleoli in LBMNCs represented by Reed-Sternberg cells was found to be about 3 and the number of AgNORs ranged between 37 and 50 depending on the histological type of Hodgkin diesease (Mamaev et al., 1997). No information has so far been presented on the number of nucleoli and on values of AgNORs during the development or apoptotic process of these cells. Therefore, the present study was undertaken to provide more information on nucleolar changes in LBMNCs; in fact such polyploid cells which are present in a small but constant number in $\mathrm{HL}-60$ cell cultures (e.g. see DSMZ - German Collection of Microorganisms and Cell Cultures) appeared to be a very convenient model for the present study. In addition, the mononucleate $\mathrm{HL}-60$ cells represented an internal control of the apoptotic process induced by the PDT. 
The results demonstrated that the apoptotic process of LBMNCs was mainly accompanied by a marked reduction of the number of AgNORs represented by silver stained particles; unexpectedly large nucleoli did not give rise to micronucleoli. Interestingly enough similar changes have previously been reported to occur in maturing bone marrow megakaryocytes (Janoutová et al., 2001).

\section{Materials and Methods}

\section{Photodynamic experiments}

Photodynamic experiments inducing apoptotis without preceding terminal maturation were described in detail previously (Grebenová et al., 1998, Smetana et al., 2000). Cultures of HL-60 cells (leukemic granulocytic precursors - European Collection of Animal Cell Cultures, Salisbury, UK) containing LBMNCs were preincubated with $1 \mathrm{mM}$ ALA in RPM I 1640 medium supplemented with 25 $\mathrm{mM}$ HEPES and $10 \%$ FCS for $4 \mathrm{hrs}$. Cells were then exposed for $1 \mathrm{~h}$ to BL (2 Osram Dulux DS9/71 discharge lamps of $2.3 \mathrm{~W}$, radiant power in the 400 $550 \mathrm{~nm}$ range) with a light dose of $18 \mathrm{~J} / \mathrm{cm}^{2}$. Subsequently, cells were incubated in the dark for 1h. The cell viability was assessed by flow cytometry using propidium iodide (PI) assay: $5 \mathrm{~mL}$ of PI (2.5 $\mathrm{mg} / 1 \mathrm{~mL}$ phosphate buffered saline) was added to $0.5 \mathrm{~mL}$ of the cell suspension $\left(1 \times 10^{5} / \mathrm{mL}\right.$ of RPMI 1640 supplemented with HEPES) and samples were submitted to flow cytometry analysis using a Coulter Epics XL flow cytometer. PI positive dead cells were expressed as a percentage of the whole number of analysed events. Cell proliferation was determined by colorimetric immunoassay based on bromodeoxyuridine ( $\mathrm{BrdU}$ ) incorporation during DNA synthesis using the Cell Proliferation ELISA BrdU Kit (Boehringer Mannheim, FRG) following manufacturer's protocol. The color reaction was recorded using Dynatech MRX microplates reader. The percentage of apoptotic cells was estimated by flow cytometry using AP0BRDU kit (Phoenix Flow System, USA) and a Coulter Epics XL flow cytometer. Three experiments were carried independently with parallel controls unexposed to PDT. Similarly as in the previous study of this laboratory most cells after PDT did not incorporate BrdU and exhibited signs of the apoptotic process as demonstrated previously (Smetana et al., 2000).

\section{Morphological cytochemical procedures}

Cell, nuclear and nucleolar morphology was observed in cytospin preparations using a Shandon II cytocentrifuge (6000 RPM for $10 \mathrm{~min}$ ). Nucleoli were visualized by a simple method for the demonstration of RNA with methylene blue in McIlvaine's citric acid buffer ( $\mathrm{pH}$ 5.3) without previous fixation (Smetana et al., 1969). In these specimens, nucleoli were classified according to size and distribution of RNA, as described previously (Smetana, 1980). The silver reaction for AgNORs was carried out under conditions which facilitated the preferential visualization of these nucleolar components as black silver stained particles over a slightly stained pale yellow nucleolar body (Smetana et al., 1999). In control specimens as well as in specimens submitted to PDT nucleoli were evaluated only in LBMNCs exhibiting clearly defined nuclei (Figure 1-4). Phase contrast microscopy was used to determine the number of nuclei per cell, the number of nucleoli per per nucleus and per cell, as well as to classify nucleoli in LBMNCs, after stainig for either RNA or AgNORs. Micrographs were taken with a Camedia digital photocamera C-4040 Z00M (Olympus, Tokyo, Japan), further magnified, processed and printed using L-view and Power Point Microsoft programs.

\section{Results}

LBMNCs derived from HL-60 leukemic granulocytic precursors were regularly present in untreated as well as in treated cultures (Figures 1-3). However, their incidence never reached more than 2 percent of cells including the apoptotic ones in treated cultures. The large cells mostly possessed 2 nuclei in both untreated and treated cultures (Table $1,2$, Figures $2,3,4)$. After PDT nuclei of LBMNCs frequently exhibited the chromatin pulverization granular condensation visible by the phase contrast microscopy (Figure 3a) which is considered to be one of signs of the apoptotic process in addition to generally known and characteristic heavy chromatin heavy condensation (Jirsová and Mandys, 1994, Smetana et al., 2000).

In specimens stained with silver reaction, the number of nucleoli per cell and nucleus in LBMNCs significantly decreased after PDT (Table 1). In these cells, PDT also significantly reduced the number of AgNORs per cell as well as per nucleus approximately to a half of the original values (Table 

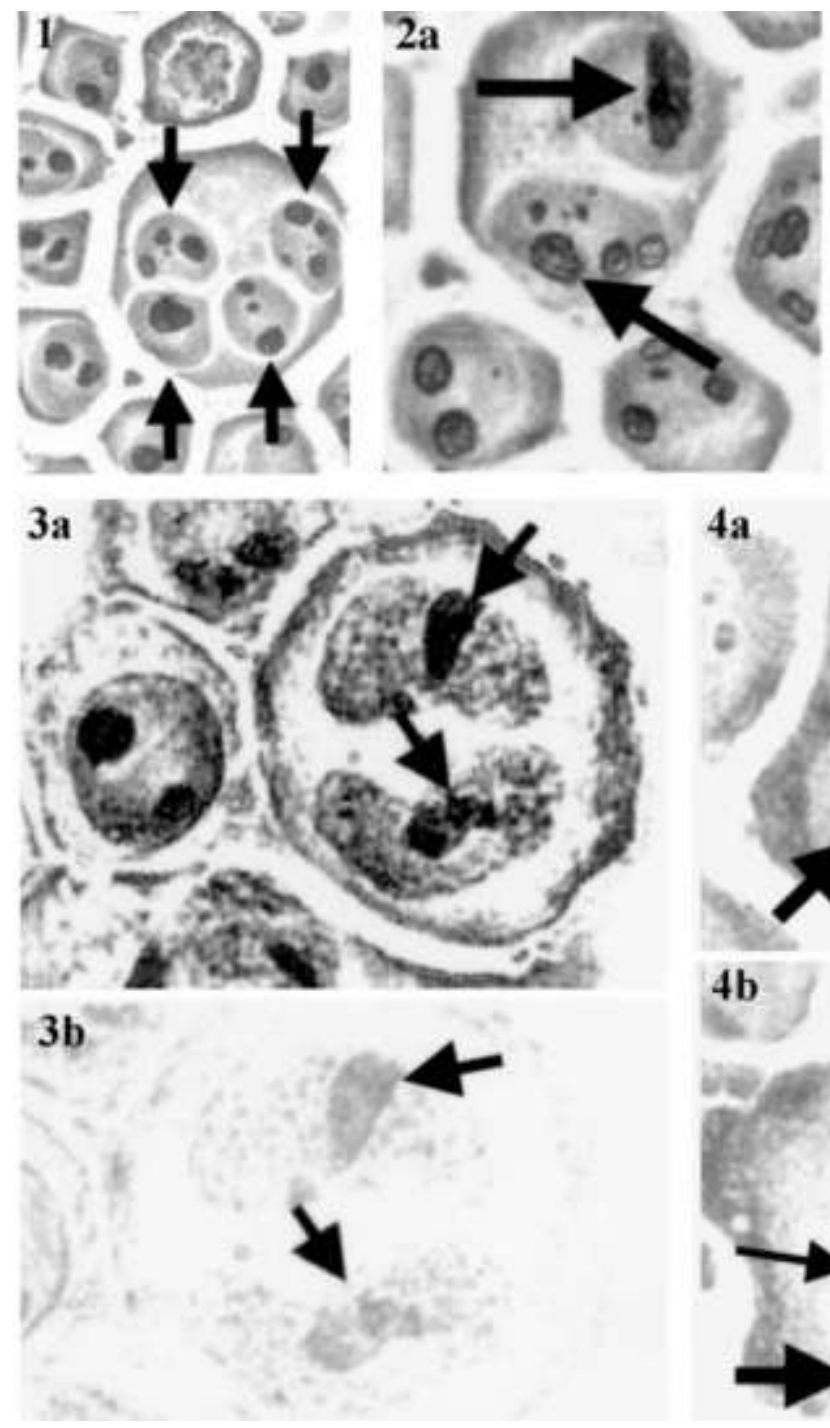
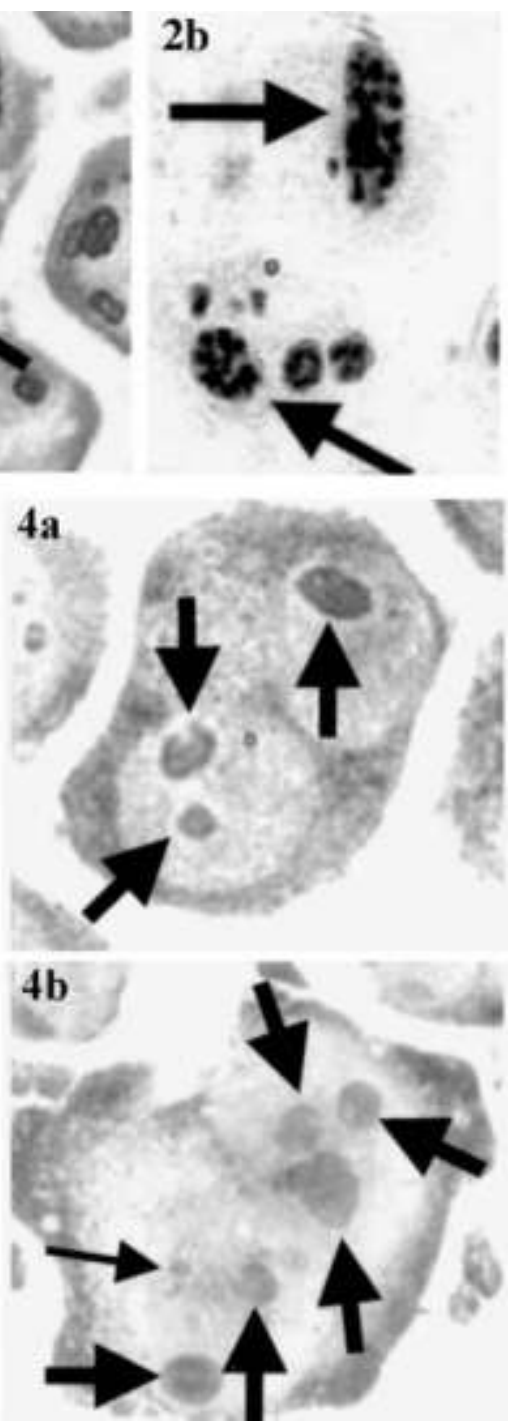

Figure 1. Phase contrast microscopy of a control untreated large multinucleate cell with 4 nuclei (arrows) stained with silver reaction. Magnification approx. 1600x. For the microphotographic procedures used in this and following Figures see Materials and Methods. Figure 2. A control untreated large binucleate cell stained with silver reaction. a - the better visualization was facilitated by phase contrast microscopy. Selected nucleoli (arrows) are magnified and visualized in the Figure $b$ by simple transmission microscopy. Note distinct and intensely silver stained AgNORs in these nucleoli. Magnification approx. 1000x (a), 1500 (b). Figure 3. PDT. A treated large binucleate cell stained with silver reaction. a phase contrast microscopy; nucleoli (large arrows) in this cell are clearly visible in nuclei with characteristic chromatin condensation-pulverization which is absent in the control cell in the Figure 1a. b - simple transmission microscopy of the same labeled and magnified nucleoli does not exhibit distinct silver stained AgNORs but the nucleolar bodies are still clearly visible. Magnification approx. $1200 \times$ (a), 1600x (b). Figure 4. Nucleoli (arrows) in large binucleate cells stained with methylene blue for RNA. Large nucleoli (large arrows) are present in both control (a) and treated cells (b). The micronucleolus or small RNA containing body (thin arrow) in the treated cell is less distinct. Magnification approx. 1800 (a), 2200 (b).
1). The decreased number or the absence of AgNORs was more distinct in large nucleoli (Figure 3). Such nucleoli, however, still exhibited a rather uniform and small positivity of the silver reaction in the nucleolar body (Figure 3 ). It should be also mentioned that no significant differences in the mean values of the nucleolar diameter were noted between control and treated LBMNCs (Table 1).

In specimens stained for RNA (Figure 4), the number of nucleoli per cell and per nucleus as that revealed by the technique also decreased in treated LBMNCs but the differences were not statistically significant (Table 2). At this occasion it should be mentioned that the number of nucleoli per cell and per nucleus in control LBMNCs was significantly smaller in these specimens (Table 2) than in those stained with the silver reaction for AgNORs (Table
1). After PDT the difference was no more significant. Concerning the incidence of main nucleolar types, LBMNCs mostly contained large nucleoli with a relatively uniform distribution of RNA (Figure 4) and other nucleolar types such as ring shaped nucleoli or micronucleoli were less frequent in these cells (Table 2). After PDT the incidence of large nucleoli in LBMNCs cells slightly decreased and that of micronucleoli increased. However, these changes were not statistically significant due to a large variability in the investigated samples (Table 2).

\section{Discussion}

The most apparent nucleolar changes in LBMNCs induced by the apoptotic process without 
preceding terminal maturation were represented by the reduction of the number of nucleoli and AgNORs per cell and per nucleus in specimens stained with silver reaction. Such changes are similar to those observed in mononuclear leukemic granulocytic precursors published previously (Smetana et al, 2000). They apparently reflect the inactivation of the nucleolar biosynthetic and cell proliferation activities as demonstrated by previous studies on other cell types (Derenzini et al., 1990, Hofgartner et al., 1979, Likovsky and Smetana, 1981, Trerè et al., 1998). On the other hand, such nucleoli still exhibited a weak positivity of the silver reaction. This phenomenon might be due to the reduced content of silver stained proteins in fibrillar centers and adjacent nucleolar regions and possibly also to their translocation from these regions; the latter are known to represent sites of RNA transcription and processing, while the former are the stores for proteins participating in this process (Schwarzacher and Wachtler, 1991, Wachtler and Stahl, 1993). The translocation and redistribution of some nucleolar silver stained proteins after the inhibition of the nucleolar RNA transcription and during apoptosis have also been reported in the literature (Busch, 1997, Chan et al., 1999, Martelli et al., 2001, Smetana et al., 2001).

The reduction of AgNORs per cell and per nucleus in LBMNCs to a half of the control values after PDT is also interesting. A similar reduction of AgNORs was noted in naked nuclei of megakaryocytes which are terminal stages of the megakaryocytic lineage which is characterized by the development of LBMNCs with irregularly shaped nuclei (Janoutová et al., 2001).

Nucleolar changes in LBMNCs stained for RNA produced by PDT were less apparent since the expected transformation of large nucleoli with a relatively uniform distribution of RNA to micronucleoli was not significant. In contrast, the persistent large nucleoli in specimens stained with silver reaction did not exhibit the presence of AgNORs or contained only their reduced number. Thus in this case large nucleoli were less active or inactive concerning the RNA transcription and AgNORs in LBM NCs were more sensitive markers of the nucleolar alteration than the incidence of main nucleolar types classified according to the size and distribution of RNA. The significantly smaller number of nucleoli per cell and per nucleus in specimens stained for RNA than in specimens stained for
Table 1. Nucleoli in LBMNCs stained for AgNORs.

\begin{tabular}{lcccccc}
\hline \hline Cells & $\mathrm{Nu} / \mathrm{Cell}$ & $\mathrm{No} / \mathrm{Cel}$ & $\mathrm{No} / \mathrm{Nu}$ & AgNORs/Cell & AgNORs/Nu & No size \\
\hline Controls & $2.3(0.1)$ & $6.7(0.7)$ & $2.8(0.2)$ & $26.2(7.4$ & $12.2(1.7)$ & $2.9(1.7)$ \\
PDT & $2.1(0.1)$ & $4.7(0.3)^{\circ}$ & $2.2(0.1)^{\circ}$ & $12.3(5.2)^{*}$ & $6.4(2.5)^{\circ}$ & $3.3(0.6)$
\end{tabular}

* significantly different from controls using the $t$-test $(p<0.005)$; ${ }^{\circ}$ significantly different from controls using the $t$-test $(p<0.02)$. The number of nuclei per cell $(\mathrm{Nu} / \mathrm{Cell})$; the number of nucleoli per cell (No/Cell); the number of nucleoli per nucleus (No/Nu); the nucleolar diameter in $\mathrm{mm}$ (No size).

Table 2. Nucleoli in LBMNCs stained for RNA

\begin{tabular}{lcccccc}
\hline \hline Cells & Nu/Cell & No/Cell & No/Nu & $\%$ LNo & $\%$ RsNo & \%MicroNo \\
\hline Controls & $2.3(0.2)$ & $5.4(0.1)^{*}$ & $2.3(0.1)^{*}$ & $71.6(5.9)$ & $19.9(6.9)$ & $11.4(6.3)$ \\
PDT & $2.4(0.3)$ & $4.0(1.4)$ & $1.6(0.8)$ & $63.2(12.5)$ & $16.1(5.1)$ & $20.6(9.2)$ \\
\hline
\end{tabular}

*statistically different from values found in specimens stained for AgNORs (Table 1) using the $t$-test $p<0.03)$. Large nucleoli ( Lno); Ring shaped nucleoli (RsNo); Micronucleoli (MicroNo). For other legend see Table 1

AgNORs noted only in control LBMNCs was not surprising. According to previous studies some small nucleoli - micronucleoli - in terminal maturation stages of nucleated blood cells may lose this nucleic acid detectable by light microscopy (Likovsky and Smetana, 2000, Smetana et al., 2001). On the other hand, the lack of such difference after PDT might be also due to the possibility that the slightly increased number of micronucleoli in specimens stained for RNA may not be distinguished from nuclear heterogeneous RNP aggregates described in apoptotic blood cell precursors (Biggiogera et al., 1997; Biggiogera and Pellicciari et al., 2000).

\section{Acknowledgements}

The present study was supported in part by research project VZ 237360001 of the Ministry of Health and the grant NC5883-3 of the Inner Grant Agency of the Ministry of Health of the Czech Republic. The authors wish to thank Dr. H. Cajthamlová and Mrs. I. Jirásková for their support and assistance.

\section{References}

Biggiogera M, Bottone MG, Pelliciari C. Nuclear ribonucleoproteincontaining structures undergo severe rearrangement during spontaneous thymocyte apoptosis. Histochem Cell Biol 1997;107:331-6. 
Biggiogera M, Pellicciari C. Heterogeneous extopic RNP derived structures (HERDS) are markers of transcriptional arrest. FASEB J 2000;14:828-34.

Busch $\mathrm{H}$. Nucleolar and nucleolonemal proteins of cancer cells. $J$ Tumor Marker Oncol 1997;12:5-68.

Chan PK, Chan FY. A study of correlation between NPM-translocation and apoptosis in cells induced by Daunomycin. Biochem Pharmacol 1999; 57:1265-73.

Derenzini M, Pession A, Trerè D. The quantity of nucleolar silverstained proteins is related to proliferating activity in cancer cells. Lab Invest 1990;63:137-40.

DSMZ; Deutsche Sammlung von Mikroorganismen und Zellkulturen GmbH: HL-60. Http://www.gbfbraunschweig.de/DSMZ/mutzmutz003.htm.

Grebenová D, Cajthamlová H, Bartosová J, Marinov J, Klamová H, Fuchs 0 , et al. Selective destruction of leukemic cells by photo-activation of 5-aminolaevulinic acid induced protoporhyrin IX. J Photochem Photobiol B Biol 1998;47:74-81.

Hofgartner EJ, Krone W, Jain K. Correlated inhibition of ribosomal RNA synthesis and siver staining by actinomycin D. Hum Genet 1979;47:329-33.

Janoutová J, Likovsky Z, Smetana K. Satellite nucleoli in the megakaryocytic lineage of rats. Physiol Res 2001;50:113-7.

Jirsová K, Mandys V. Induction of micronuclei and granular chromatin condensation in human skin fibroblasts influenced by cisplatin (cisDDP) in vitro. Mutat Res 1994;310:37-44.

Likovsky Z, Smetana K. Further studies on the cytochemistry of the standardized silver staining of interphase nucleoli in smear preparations of Yoshida ascitic sarcoma cells in rats. Histochemistry 1981; 72:301-13.

Likovsky Z, Smetana K. Nucleolar coefficient of granulocyte precursors and granulocytes after visualization of nucleoli by two different methods. Acta Histochem 2000;102:95-102.

Mamaev NN, Medvedeva NV, Shist VF, Markochev AB, Pasternak ND. Nucleoli and AgNORs in Hodgkin's disease. J Clin Molec Pathol $1997 ; 50: 149-52$
Martelli AM, Zweyer M, Ochs RL, Tazzari PL, Tabellini G, Narducci P, et al. Nuclear apoptotic changes: an overview. J Cell Biochem 2001; 82:634-46.

Schwarzacher HG, Wachtler F. The functional significance of nucleolar structures. Ann Genet 1991;34:151-60.

Smetana K. Nucleoli in maturing blood cells. In: S. Roath, ed. Topical Reviews in Haematology. Vol. 1, Wright: Bristol; 1980. p. 115-37.

Smetana K. Structural features of nucleoli in blood, leukemic, lymphoma and myeloma cells. Eur J Histochem 2002;46:125-32.

Smetana K, Busch R, Chan PK, Busch H. Immunocytochemical localization of nucleophosmin and RH-II/Gu protein in nucleoli of HeLa cells after treatment with actinomycin D. Acta Histochem 2001; 103:325-33.

Smetana K, Cajthamlová H, Greberová D, Hrkal Z. The 5-aminoloaevulinic acid-based photodynamic effects on nucleoli and nucleoli of $\mathrm{HL}-60$ leukemic granulocytic precursors. J Photochem Photobiol B Biol 2000;59:80-6.

Smetana $\mathrm{K}$, Jirásková I, Perlaky L, Busch $\mathrm{H}$. The silver reaction of nucleolar proteins in the main structural compartments of ringshaped nucleoli in smear preparations. Acta Histochem 1999;101: 167-83.

Smetana K, Jiraskova I, Smetana K Jr, Cermak J. A short note on micronucleoli in the course of terminal maturation of human erythroblasts. Folia Biol (Praha) 2001;47:14-7.

Smetana K, Lejnar J, and Potmil M. A further contribution to the demonstration of RNA and nucleli in smear preparations. Folia Haematol 1969;91:381-4.

Trerè $D$, Pession A, Derenzini M. The silver-stained proteins of interphasic nucleolar organizer regions as a parameter of cell duplication rate. Exp Cell Res 1998;184:131-7.

Undritz E. Hämatologische Tafeln. Sandoz, Basel, 1972.

Wachtler F, Stahl A. The nucleolus: a structural and functional interpretation. Micron 1993;24:473-505. 
K. Smetana et al. 